\title{
International Journal of
}

\section{Information Technology and Computer Science}

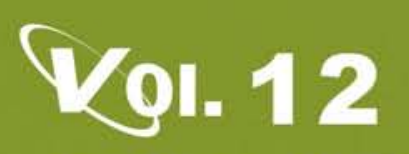

No. 6 Dec. 2020
IJITCS Vol.12

Http:// www.mecs-press .org

Vol.12 No.6 December 2020

\section{Modern Education}

and Computer Science PRESS 
International Journal of Information Technology and Computer Science (IJITCS)

ISSN Print: 2074-9007, ISSN Online: 2074-9015

Volume 12, Number 6, December 2020

\section{Contents}

\section{REGULAR PAPERS}

Applying Clustering and Topic Modeling to Automatic Analysis of Citizens' Comments in 1 E-Government

Gunay Y. Iskandarli

FBSEM: A Novel Feature-Based Stacked Ensemble Method for Sentiment Analysis

Yasin Görmez, Yunus E. Işılk, Mustafa Temiz, Zafer Aydın

Active Selection Constraints for Semi-supervised Clustering Algorithms

Walid Atwa, Abdulwahab Ali Almazroi

Case-Based Reasoning Framework for Malaria Diagnosis

Eshetie Gizachew Addisu, Abiot Sinamo Boltena, Samson Yohannes Amare

Managing Data Diversity on the Internet of Medical Things (IoMT)

Iram Mehmood, Sidra Anwar, AneezaDilawar, IsmaZulfiqar, Raja Manzar Abbas 